\title{
Study on the Employment Service in China's Resource-exhausted Cities
}

\author{
Ge Shaolin ${ }^{1}$ and Han Quanfang ${ }^{2}$ \\ ${ }^{1}$ Yunnan University of Economics and Finance, Kunming, P.R.China, 650221 \\ ${ }^{2}$ Institute of Sociology Chinese Academy of Social Sciences, Beijing, P.R.China, 100732 \\ ( 1.geshaolin72@yahoo.com.cn, 2 .hqfang666@163.com)
}

\begin{abstract}
The employment issues in resource-exhausted cities are social issues faced by various countries in the world in the process of industrialization, and improving the level of employment service is the key for solving the unemployment problem in resource-exhausted cities. This paper adopts the comparative research method to analyze the characteristics and manifestations of employment issues in China's resource-exhausted cities and Ruhr of Germany, Lorraine of France, Houston of USA, and Kyushu of Japan in the form of data, and then puts forward the targeted countermeasures and suggestions on improving the employment service in resource-exhausted cities in combination with China's national conditions.
\end{abstract}

Keywords: resource-exhausted cities, employment service, employment policy

\section{Introduction}

Resource-exhausted cities refer to the cities whose exploitation of mineral resources enters into the later period with the accumulative reserves already exploited exceeding $70 \%$ of the exploitable reserves. The transition issues of resource-exhausted cities are prominent problems various countries in the world have gone through or are going through in their social and economic development, such as the Ruhr mining area in Germany and the Lorraine mining area in France. The National Development and Reform Commission (NDRC), the Ministry of Land and Resources and the Ministry of Finance of the People's Republic of China confirmed 69 resource-exhausted cities (counties, districts) in 2008, 2009 and 2012 successively. In order to support the transition of recourse-exhausted cities, the NDRC sets up the special investment projects within central budget for recourse-based cities to absorb employment, utilize resources comprehensively, develop alternative industries and cultivate diversified industry system, and the central finance offers transfer payment funds to the 69 cities.

\section{Study on the Employment Service in Foreign}

\section{Resource-exhausted Cities}

Resource exhaustion is a problem of industrialized society. From Ruhr of Germany, Lorraine of France, to Houston of USA, Baku of the former Soviet Union, and Kyushu of Japan, the mining cities of these countries have all suffered from the 
pain caused by resource exhaustion and economic recession.

\subsection{Unemployment Problem in Foreign} Resource-exhausted Cities

In Ruhr, Germany, the number of employees decreased from 489,000 to 197,000 during 1957 1971 and further decreased to 70,000 in 1996. Germany's unemployment rate was $10.3 \%$ in 1996 , while the unemployment rate in Ruhr reached as high as $15 \%-16 \%$ at that time. In Lorraine, France, the number of employees in the iron and steel industry decreased to 14,372 in 1993 , only $1 / 3$ of that in 1984, and the number of coal workers decreased from 24,000 to 9,743. In Kitakyushu, Japan, the number of coal workers was 470,000 in 1961 but now only 3,000 people are engaged in this industry. Because of the recession of the iron and steel industry, the leading industry in Pittsburgh, USA, the total unemployment in the manufacturing industry exceeded 100,000 during 1978-1987, while the proportion of iron and steel workers in that district was less than $5 \%$. From the 1970 s to the early 1980s, the iron and steel output in Birmingham declined by $45 \%$ and the manufacturing industry lost 100,000 jobs, with the unemployment rate reaching $20 \%$. [1]

\subsection{Employment Service in Foreign Resource-} exhausted Cities

\subsubsection{Labor transfer modes}

There are mainly three modes for the labor transfer in foreign resource-exhausted cities. The first mode is the industry update mode, which takes advantage of the funds, technologies and talents accumulated by resource exploitation, or makes use of the brandnew industrial clusters established with external forces and basically independent of original resources, to develop new industries and accommodate labor force. The second mode is the industry extension mode, which develops downstream industries, sets up the industrial clusters for the further processing and utilization of resources and accommodates labor force on the basis of original resource exploitation industries. The third mode is the compound mode, which is manifested as the industry extension mode at the initial stage of industry transition. Under this mode, the increasing emerging industries and the formation of diversified industrial structure finally contribute to integrated cities, and the labor force transfers to diversified industries. [2]

\subsubsection{Government grants economic aid to the} re-employment of laid-off miners

The US government provided financial aid such as grants and loans for some old and abandoned coal mines in the 1960s. For enterprises in Ruhr, 
Germany which create jobs, the government grants a subsidy of 50,000 mark for each job created, and the government provides the companies which make investment in Ruhr with a grant amounting to $10 \%$ of their aggregate investment. [3]

\subsubsection{Employment policy coordinates with} industrial policy

The Japanese government especially emphasizes that employment issues are the central issues to be solved for the Japanese economy. It formulates a series of policies and regulations to guarantee the transition of the employment structure of surplus staff in declining industries. For industries that decline because of national economic and industrial policy such as the mining industry and the textile industry as well as the affected regions, the country should assume the responsibility of job placement.

\section{Current Situation of the Employment Issues in China's Resource-exhausted Cities}

\subsection{Large Number of Laid-off Workers}

The laid-off workers in resource-based cities mainly include the workers downsized from resource-based enterprises because of the shrink of resource-based industries or the reform of stateowned enterprises, the laid-off workers of the affiliated enterprises which become stagnant because of the shrink of resource-based industries, and the newly increased unemployed workers. In resource-based cities and especially those with exhausted resources, the absolute number of laidoff workers is often large and the laid-off time is often concentrated. This kind of concentrated and homogeneous unemployment often has a great influence on the society(Form 1). [5] [4]

Form 1 Number of the Laid-off Workers in Some Resource-exhausted Cities in China in 2002

\begin{tabular}{|l|l|l|l|l|l|}
\hline City & \multicolumn{1}{|c|}{$\begin{array}{c}\text { Number of } \\
\text { Laid-off } \\
\text { Workers } \\
\text { (Unit:10,000) }\end{array}$} & $\begin{array}{c}\text { Proportion in } \\
\text { the City's } \\
\text { Total } \\
\text { Population } \\
(\%)\end{array}$ & City & $\begin{array}{c}\text { Number of Laid- } \\
\text { off Workers } \\
\text { (Unit:10,000) }\end{array}$ & $\begin{array}{c}\text { Proportion in the } \\
\text { City's Total } \\
\text { Population }(\%)\end{array}$ \\
\hline Datong & 7.5 & 5.45 & Huainan & 4.7 & 3.34 \\
\hline Xiaoyi & 1.1 & 2.59 & Huaibei & 2.8 & 3.43 \\
\hline Wuhai & 1.9 & 4.61 & Pingxiang & 3.9 & 4.94 \\
\hline Fuxin & 15.6 & 19.91 & Hebi & 2.4 & 4.66 \\
\hline Beipiao & 5.5 & 8.91 & Pingdingsh & 2.9 & 3.18 \\
\hline Fushun & 12.4 & 8.92 & Tongchuan & 2.8 & 3.76 \\
\hline Liaoyuan & 2.7 & 6.04 & Lengshuiji & 1.8 & 3.90 \\
\hline Yichun & 6.5 & 7.71 & Gejiu & 1.5 & 4.71 \\
\hline Hegang & 5.4 & 7.81 & Panzhihua & 3.1 & 6.19 \\
\hline Shuangyash & 6.5 & 12.83 & Baiyin & 2.9 & \\
\hline
\end{tabular}

Data source: Wang Qingyun. Study on the Economic Transition of Resource-based Cities. China Economic Press, 2003: 45. 


\subsection{Unreasonable Employment Structure and} Narrow Employment Channels

Compared with other resource-based cities and nonresource-based cities, the industrial structure in resource-exhausted cities is too single, the private economy and the individual economy are not developed and little employment is absorbed. This may be an important reason why the employment pressure in resource-exhausted cities becomes heavier. The narrow employment channels influence the employment situation in resource-exhausted cities. The job vacancies-to-seekers ratio of resourcebased cities is lower than that of general cities, which indicates that the imbalance between labor supply and demand is more prominent in resource-based cities. The tertiary industry in non-resource-based cities absorbs $72.6 \%$ workers, while the proportion in resource-exhausted cities is only $64.7 \%, 8 \%$ less. In resource-based cities, the proportion of workers in the secondary industry is higher. In non-resource-based cities, the workers engaged in the mining industry, manufacturing industry and building industry account for $25.3 \%$, while the proportion reaches $36.84 \%$ in resource-based cities. For the middle-aged resourcebased cities, the proportion of workers in the secondary industry is the highest, reaching $38.45 \%$, while the proportion for the cities with exhausted resources is $33.9 \%$ (sampling survey data of 66 cities in 2002 issued by the Ministry of Labor and Social Security).

\subsection{Imperfect Employment Service System}

The employment service system in resourceexhausted cities is imperfect. Firstly, the equal unified employment system between urban and rural areas has not been fully established, there are employment discriminations, and the household registration system, rural land system, education and health system and employment access standards need to be perfected and unified. Secondly, it is necessary to establish and perfect the public employment service system, strengthen the construction of public employment service institutions, give full play to the role of street labor security offices and township labor security institutions in promoting employment, perfect the contents of employment service, and normalize the procedures of employment service. Thirdly, the vocational training system is imperfect, so it is required to provide a comprehensive set of convenient and fast "one-stop" services of skill training, employment guidance, vocations introduction, security agency and legal consulting for workers and to continuously improve the institutionalization, professionalization and socialization of employment service. Fourthly, the employment assistance system is imperfect, so it is necessary to further establish and perfect the system and adopt various effective measures to support and assist the people with difficulties in getting employed.

\subsection{Insufficient Public Service Capability}

Resource-exhausted cities also have the tendency of "administerization" and "bureaucracy" in talent management, and the talent flow is still restricted in terms of location, region, sector, industry and identity. As the employment service is increasingly socialized, the public employment service sector in resource-exhausted cities should update the service concept and formulate flexible and diverse policies for flexible talent flow. With respect to information work, it is necessary to realize the combination of reception service and informationalized service, improve work efficiency to make sure people can be served in time, broaden the application fields of information technology, reinforce the supporting role 
of information technology in promoting the public employment service capability, and widen the informationalized service channels.

\subsection{Insufficient Employability of Laid-off Workers}

The laid-off workers in resource-based cities often have backward ideas and poor adaptability to market economy. As a result, employees are strongly dependent on their enterprises and the employees of resource-based enterprises have a strong dependence on and a sense of belonging to mining areas. Employees have a strong complex of "absolute equalitarianism irrespective of one's performance" with the government and state-owned enterprises, which gradually leads to a series of outdated employment ideas that don't adapt to the requirements of market economy. [7] Due to the particularity of resource-based cities in the process of formation and development, the urban laid-off workers usually have low quality and poor reemployment ability, and are reluctant to find other jobs and not stable. Resource exploitation is an industry requiring heavy physical labor and the workers only master single techniques. In addition, the workers in mining areas and their relatives are mainly from rural areas and most laid-off workers are aged between 40 and 50, whose scientific and cultural qualities are universally low and it is difficult for them to satisfy the employment requirements of market economy.

\section{Countermeasures and Suggestions on Perfecting}

the Employment Service in Resource-exhausted Cities

\subsection{Perfect the Employment Promotion and Re- employment Policy}

Give precedence to enlarging employment in the economic and social development of resource-based cities, and strengthen the construction of the employment skills training system. Give play to the role of government investment and major project construction in driving the employment. Support the development of labor-intensive industries, service industries and small and micro enterprises, and vigorously develop the family service industry. Perfect and implement small-sum secured loans, finance discount and site arrangement to encourage entrepreneurship, improve the entrepreneurship service system, and promote various groups to start a business to create employment. Speed up the establishment of a professionalized, informationized and industrialized human resources service system, and intensify employment agencies and employment information service. Develop public welfare jobs through multiple channels, and give priority to supporting the re-employment of the groups with difficulties such as laid-off mine workers, laid-off forest workers, people who become disabled because of work-related injury, residents relocated because of shantytowns transformation, and land-lost peasants.

\subsection{Strengthen Social Security and Medical and Health Services}

Further perfect the social security system concerning basic old-age pension, basic medical care, unemployment, work-related injury and childbirth, actively urge various groups with difficulties to participate in social insurance, broaden the coverage of social insurance, strive to make everyone in 
straitened circumstances have access to subsistence allowances, and gradually enhance the security level. Gradually solve the remaining problems of the participation in medical insurance of the retirees of closed or bankrupt collective enterprises and the incorporation of the workers with "old work-related injury" into work-related injury insurance. Perfect the urban and rural subsistence allowances and social assistance system. Solve the social security issues of land-lost peasants by conducting studies. Accelerate the construction of social security service facilities in mining areas, and set up social security management service network. Perfect the grassroots medical health service system, and enhance the service level and emergent rescue ability of the medical institutions in mining areas. Reinforce the prevention and treatment of the occupational diseases and common diseases of mine workers such as pneumoconiosis, chronic gastritis and skin disease.

\subsection{Boost the Equalization of Public Employment} Service

Expand the employment service scope for the rural workers in resource-exhausted cities, implement the employment and unemployment registration system, and incorporate all urban and rural workers conforming to unemployment registration conditions to the unemployment registration scope to enjoy the corresponding supportive policies and employment service. Strengthen the employment assistance to the urban and rural people with difficulties in getting employed, and carry out the trinitarian assistance measures of job, training and policy for these people, namely provide job information once a month, provide training opportunity once a year and provide policy support at any time. Implement the employment promotion policy for urban and rural workers, and the public employment service institutions at different levels should register the implementation situation of the relevant system and make various employment and entrepreneurship promotion policies benefit every urban and rural worker.

\subsection{Boost the Standardization of Public Employment Service}

Normalize the service process in resource-exhausted cities and establish a troubleshooting mechanism for problems. Innovate service mode, and provide "customized" services in terms of training and recruitment for the employment difficulty of employers. Increase the service efficiency, extend the public employment service items that provide convenience for service objects to streets and communities, and subject them to the administration of grassroots public employment service institutions in streets or communities. Perfect the performance evaluation, carry out the grade evaluation for talent service agencies, improve the public employment service performance, formulate a performance evaluation system for the public employment service platforms in streets and communities, and earnestly enhance the efficiency and level of public employment service.

\subsection{Boost the Informatization of Public Employment Service}

Boost the upgrading and rebuilding of the integrated information system of public employment in resource-exhausted cities, build an informationalized service platform that integrates information acquisition, business handling, online convenience service and monitoring and control analysis, and realize the optimization and upgrading of the information management of employment service work as well as the data unification and business 
collaboration of social security and rightsafeguarding information.

\section{Conclusions}

Employment is vital to people's livelihood. Resource exhaustion alters the foundation of the entire urban society and results in dramatic changes in living conditions, lifestyle and social emotions. As a laborintensive industry, the resource-based industry has many employees with many children, which leads to a huge employment pressure. In recent years, because of the technological progress, the increased degree of mechanization in mines, as well as the exhaustion and closure of some mines, employees working in mines have sharply decreased. Therefore, when cultivating and developing alternative industries, resource-based cities firstly need to consider how to solve employment issues, positively develop the industries with a strong ability to absorb employment, and make use of the existing buildings and facilities in mining areas, the abundant forest resources and sound ecological environment in the forest region, and the re-employment projects for the residents relocated because of shantytowns transformation to vigorously develop new alternative industries to fundamentally solve the problem of employment difficulty. In addition, they should also try to break the internal dual structure, vigorously enlarge employment, promote the social security level, perfect the basic public service, improve the production and living environment, promote social harmony and stability, steadily promote the quality and level of urbanization, and make resource exploitation and economic development achievements benefit the masses of the people. The concrete measures for realizing the above include promoting employment and re-employment, accelerating the shantytowns transformation, strengthening social security and medical and health services, and creating a safe and harmonious production and living environment.

\section{Acknowledgments:}

Fund: This article sported by Chinese National Social Science Foundation(13CSH088). China Postdoctoral Scientists Science Foundation (2012M510682). Ministry of Education, Humanities and Social Sciences Youth Fund(12YJC840007). Ministry of Education, Humanities and Social Sciences western and Border areas Fund (11XJA840002).

\section{References}

[1] Zhao Wenxiang. Study on the Labor Transfer Law and Employment Issues in Resourceexhausted Cities, China Labor and Social Security Press, 2007.

[2] Guo Peizhang. Study on China's Urban Sustainable Development [M]. Beijing: Economic Science Press, 2004.

[3] Mai Lichen. A Comparative Study of Unemployment and Re-employment between China and Japan at the End of the 20th Century [J]. Japan Studies, 2002(4).

[4] Qian Xiaoying. On Japan's Employment Policy [J]. China Labor, 1998(8).

[5] Li Yutong, Wang Haihong. Analysis of the Employment Issues in China's Resource-based Cities. Population Journal, 2008(4).

[6] Wang Qingyun. Study on the Economic Transition in Resource-based Cites. Beijing: Economic Science Press, 2003.

[7] Li Yutong. Analysis on the Employment Problem of Resources-based Cities in Northeast China and Countermeasures. Population Journal, 2007 (2). 